\title{
El coraje como actitud del ciudadano o sujeto político $^{2}$
}

\author{
The courage as an attitude of the citizen as a political subject \\ A coragem como uma atitude do cidadão como sujeito político
}

\begin{abstract}
Resumen
El presente texto aborda las nociones de sujeto político y ciudadanía desde las posibilidades de militancia y respuesta a la violencia y la realidad. El debate planteado se enriquece con planteamientos de Michel Foucault, Hannah Arendt, Jacques Ranciere, Howard Zinn y Henry Thoureau. De igual modo, la reflexión sobre la experiencia de Gandhi nutre la discusión por cuanto la no-violencia es un posicionamiento legítimo frente a las acciones violentas.
\end{abstract}

Palabras clave: sujeto político, ciudadanía, no-violencia, militancia.

\section{Recibido: 7 de marzo de 2016, evaluado: 14 de abril de 2016, aprobado: 17 de abril de 2016}

1 Director de Investigaciones, Corporación Universitaria Minuto de Dios_Uniminuto—, Sede Principal. Correo electrónico: cgjuliao@gmail.com

2 Algunas ideas de este texto se presentaron también en Bucaramanga, el 20 de mayo de 2016, en el marco del I Foro "Rol de la academia dentro del proceso de Paz y Posconflicto", organizado por las IES, Uniminuto, ESAP y UTS. 


\section{Abstract}

The present text addresses the notions of political subject and citizenship from the possibilities of militancy and counterviolence and the reality. The formulated debate enrichens with the expositions of Michael Foucault, Hannah Arendt, Jacques Ranciere, Howard Zinn and Henry Thoureau. In the same way, the reflection about Gandhi experience nourish the discussion since the non-violence appears as a legitimate positioning against the violent actions.

Keywords: political subject, citizenship, non-violence, militancy.

\section{Resumo}

O presente texto aborda as noçôes de sujeito político e cidadania desde as possibilidades da militância e resposta à violência e a realidade. $\mathrm{O}$ debate proposto enriquece-se com propostas de Michel Foucault, Hannah Arendt, Jacques Ranciere, Howard Zinn e Henry Thoureau. Do mesmo jeito, a reflexão sobre a experiência de Gandhi nutre a discussão porquanto a não-violência é um posicionamento legítimo em frente às açôes violentas.

Palavras-chave: sujeito político, cidadania, não-violência, militancia. 


\section{Introducción}

\section{Coraje es caminar hacia el peligro, a sabiendas de los riesgos (Gayle Forman)}

Se pretende abordar el problema del ciudadano, como sujeto político, desde la perspectiva de la subjetivación. Esto significa pensarlo como un proyecto siempre en curso (construcción de ciudadanía), y no como algo dado o terminado. Lo que se afirma es que el ciudadano (sujeto político) está en construcción permanente, no es algo existente, sino un proyecto a generar.

Por lo anterior las siguientes preguntas se tornan fundamentales: ¿cómo construir ciudadanía? ¿Qué camino seguir para construirse como sujeto político? Si aquí no se distinguen los conceptos "ciudadano" de "sujeto político" es porque se asume que la ciudadanía no es algo dado o heredado, sino que es pura acción, fruto del compromiso; tampoco como en un proceso de fabricación de algo, pues corresponde a cada uno lograr la posición de animal político, pasando de sujeto responsable en su propia acción cotidiana a la de sujeto dueño de sí mismo, como auténtico ser político en todas sus formas. Esta transformación de lo pre-político a lo político, en total compromiso con el propio desarrollo ciudadano, requiere plantear que la subjetivación política es la real diferencia entre lo pre-político y lo político. Entonces, ¿cuál es la auténtica actitud ciudadana? Siguiendo a la tradición filosófica que ha pensado lo político desde la perspectiva de la acción, desde la praxis, y en especial a Hannah Arendt (2005), se sostiene aquí que es el coraje, virtud inspirada en la actitud parresiástica que promovieron los antiguos pensadores griegos.
Entonces, hablar de subjetivación política nos conduce a la cuestión del llamado "coraje" o audacia política, como característica y virtud esencial del auténtico ciudadano, que constituiría su diferencia frente al no-ciudadano. Siempre desde una filosofía política de la acción, sería el paso del observar, interpretar y comprender un problema, concreto y vivido, a la voluntad praxeológica de actuar para resolverlo. Así como Thoreau escribió: "Hay miles de personas que por principio se oponen a la esclavitud o a la guerra pero que, en la práctica, no hacen nada para acabarlas" (2007, p. 27), se trata del paso praxeológico del ver (situar y comprender situación) al actuar (decisión valerosa de solucionarlo). Pero como las personas por lo general somos pragmáticas, temerosas $\mathrm{o}$ precavidas, siempre esperamos que sea otro quien comience a actuar. Pues bien, el auténtico ciudadano es quien se atreve a dar ese "primer paso", convencido de que otros lo seguirán y así su "praxis testimonial" beneficiará a todos.

Ciudadano es entonces quien con coraje transforma sus análisis, palabras y pensamientos en actos y compromisos, pasando de la comprensión de una situación, y de la indignación que esta puede haberle generado, a la acción. Ahora bien, esto no excluye asumir que algunas palabras o discursos ya son actos en sí mismos y, por ende, que hay palabras que son parresiásticas o valientes con sólo decirlas; por ejemplo, cuando se denuncia públicamente una injusticia en vez de quedarse callado ante ella, o cuando se dice la verdad (o se enseña lo que se cree) sin temor a las consecuencias que ello pueda traer. Por ende, lo que aquí es pasar praxeológicamente del ver al actuar es el paso de una palabra cautelosa o temerosa, que se expresa en lo privado o se queda en los pensamientos, a una palabra política que se dice sin temor y públicamente. Así un pensamiento libre es una acción política. 
Cuando esto se hace el ciudadano (sujeto político), con su pensamiento, su palabra y su acción, en este caso totalmente coherentes, ingresa realmente en el espacio público. Sea con una palabra valiente o con una acción pertinente, el propio ciudadano es quien ejerce su acción en ese espacio político, liberando sus ideas, creencias o convicciones de su pensamiento para exponerlas (en el sentido de decirlas y de "exponerse" al hacerlo) y encarnarlas de modo praxeológico en actos concretos. Gros lo señala cuando expresa que "el coraje es principalmente exponerse, en el sentido de que sólo hay verdadero coraje cuando uno se exterioriza" (2006, p. 22). El coraje es entonces una cualidad que se actualiza cuando se exterioriza porque no basta con las intenciones, dado que su esencia es precisamente "actualizar las intenciones".

Como alguna vez lo señaló Nelson Mandela, la valentía no es ausencia de miedo, sino el esfuerzo para triunfar sobre éste. El valiente no es quien no siente miedo, sino quien logra conquistar dicho miedo y, en consecuencia, actúa con coraje. Hay que decir también que el sujeto o ciudadano que actúa con valentía no espera la menor recompensa o gratificación, pues el coraje es un ejercicio de total gratuidad; más allá de la satisfacción de sentir que se hizo lo correcto, que se actuó coherentemente con las propias ideas, no se puede esperar ningún otro beneficio. Simplemente el coraje es levantarse para defender aquello en lo que se cree.

Pero hace falta aclarar algo más: el concepto de coraje no es tan consistente que pueda atribuírsele un solo sentido. Como lo plantea Manuel Cervera (2012) se podría establecer una tipología del coraje político o ciudadano: el coraje de la verdad (que Foucault llama parresia y que se puede encarnar en la figura del militante político), el de la libertad (que Arendt considera heroísmo y de algún modo refleja a la persona del revolucionario) y el de la no-violencia (satyagraha para Gandhi, entendida como la actitud de la desobediencia civil).

Aquí agregamos una cuarta posibilidad, que de algún modo podría recoger las tres anteriores: el coraje de enseñar, cuando muchos afirman que el oficio de maestro es una tarea necesaria para la sociedad, pero imposible de realizar, sobre todo por aquello de la autonomía del sujeto que aprende y es el único responsable de su propia formación.

La historia nos presenta ejemplos diversos de cada uno de estos tipos de coraje: Sócrates, Montaigne, Rousseau o Simone Weil, con diversos tipos de discurso (orales o escritos) que expresan la propia verdad y persuaden por su coherencia; Leon Trotsky, Che Guevara, George Orwell o Flora Tristán, que rechazaron el orden establecido y lo arriesgaron todo por su propia verdad; Henry Thoreau, Mahatma Gandhi o Martin Luther King, e incluso el movimiento hippie, como ejemplos de resistencia civil frente a lo establecido; y nuevamente Sócrates, junto a maestros como María Montessori, Antón Makarenko, Celestín Freinet o Paulo Freire quienes, pese a todo, lograron ejercer el "oficio de maestro" y nos legaron auténticas revoluciones pedagógicas.

\section{La militancia de lo veraz (parresia): hacer de la vida un testimonio}

Este acercamiento al concepto parresía (testimonio audaz de la verdad) se inspira en la reivindicación del concepto y su práctica realizado por Foucault en los últimos dos años de su vida, en sus cursos en el Colegio de Francia (París), que quedó plasmada en tres libros bastante significativos: La hermenéutica del sujeto, El gobierno de sí y de los otros y El coraje de la verdad: el gobierno de sí y de los otros II. Hay que reconocer en todo ello un significativo viraje en su reflexión filosófica, aún no considerado plenamente en los estudios críticos sobre su vida y obra. Efectivamente, Foucault se remonta a los sabios griegos, en especial Sócrates, Platón y luego, a las escuelas greco-romanas: estoicos (Epicteto, Séneca y Marco Aurelio), los cínicos (Diógenes de Sínope) y su sabiduría naturalista y sincera, para culminar en los Padres de la Iglesia, llevando a plenitud el sentido filosófico de la parresía o veridicción en una aproximación teológica, que desborda al mismo filósofo. 
Se trata de asumir una postura ética haciendo de la propia vida un "testimonio de la verdad" que tendrá efectos políticos.

Foucault había planteado la cuestión del orden de los discursos como producción de los saberes, normas de comportamiento y modos de subjetivación, en el despliegue de una especie de máquina de poder-saber cuyos protagonistas (el psiquiatra y los locos, por ejemplo) parecen no tener margen de maniobra subjetiva. Discursos y dispositivos producen literalmente sujetos, sometidos al lugar que les es asignado. Ahora este último Foucault (2008) plantea un giro con la problemática del "cuidado de sî" y de la palabra veraz (parresía), parece oponerse a esta lógica del orden discursivo, pues interroga la posición del sujeto ya no como sujeción o producción, sino como acto, es decir, como ética: hay que pensar al sujeto como actor político, que expresa públicamente lo que molesta, lo que no es agradable de oír pero debe ser dicho, reversando así la cuestión del poder y la democracia. La parresia se define, entonces, como la toma de la palabra del ciudadano valiente que, rechazando la complacencia y la adulación, decide decir al pueblo la verdad, cualquiera que sea el precio (para el pueblo, pero sobre todo para él mismo). Por ello se puede hablar de militancia de lo veraz.

Este estilo de vida del hombre valiente, que toma la palabra para decir la verdad, ha sido constante en el curso de la historia. Según Foucault, el ascetismo cristiano medieval permitió que este modo de existencia iniciado por los cínicos pasara a la modernidad, donde se encuentra la figura del militante político que, como Simone Weil, no solo denuncia lo que no acepta (para ella el capitalismo imperialista y la crueldad franquista), sino que va más allá pues exige un coraje real al dirigirse a sus amigos más cercanos, con una verdad que es autocritica; o como lo dice ella: una "reflexión para desagradar" (1960, p. 218).
Guardadas las diferencias, es el mismo caso de Sócrates que encarna la relación entre filosofía y vida ciudadana, entre filosofía y parresía, y entre vida ciudadana y parresía. Sócrates muestra en qué consiste ese cuidado de sí centrado sobre cierto modo de veridicción y que pretende configurar un tipo concreto de existencia ciudadana, incluso si ello lo hace incomprendido por sus más cercanos amigos.

Es que aún entre los suyos, o mejor, sobre todo entre los suyos, el militante es mal visto; sacrifica su nombre al decir la verdad y obrar con justicia y, por su coraje, se expone a ser marginado. Al presentarse como el más fiel a la causa es estigmatizado. El militante, por su verdad, siempre ha desequilibrado al revolucionario quien, al ponerse del lado de los dominados, se cree libre de toda crítica. Ahora bien, militante no necesariamente significa partidario. Este último es quien expresa su verdad comprometiéndose con un partido político. Pero, hay que distinguir radicalmente el espíritu militante del partidario: la diferencia esta en la forma como abordan la problemática y como reflexionan. Ambos luchan por la verdad; pero mientras el militante lo hace de forma pensante (se podría decir filosófica), el partidario avanza a ciegas. Weil (1960) dice que estos últimos piensan "en cualquier dominio, solo tomando posición "a favor" o "contra" una opinión. Después se buscan los argumentos, según el caso, sea a favor, sea en contra" (p. 69). El error es tomar primero posición, y luego justificarla. Sócrates, al contrario, realmente preocupado por la verdad, procede de forma contraria: observa, recoge, selecciona, clasifica y organiza la información. Y sólo después asume una opinión racional, conforme a la verdad, en tanto esto es posible al razonamiento humano. $\mathrm{Y}$ a ese error del partidario se agrega el abordar los problemas de modo dualista (a favor/en contra) sin verlos en toda su complejidad. 
En definitiva, la parresia no es sólo coraje en acto (encarnar la verdad en la vida como lo hicieron los cínicos griegos) o en palabra (decir públicamente la verdad que molesta, como Sócrates): ella es también coraje de pensamiento o "coraje intelectual" para evitar el simplismo partidista, pues es tentador (por ser sencillo) eludir la reflexión adhiriéndose acríticamente a lo que el partido (o el sistema) nos define. Porque, como lo señala Weil (1960) "nada es más confortable que no pensar” (p. 60).

\section{El heroísmo veraz: ser revolucionario}

El coraje de la libertad ${ }^{3}$ concepto asociado a la polis griega, concierne también al revolucionario de los tiempos modernos, pese a que la historia hace que el término "revolución" siempre se asocie a las peores atrocidades. Por eso no sorprende los temores de algunos frente a la inclinación totalitaria del héroe arendtiano quien, en nombre de la libertad, supera su miedo a la muerte y se expone públicamente pese a los riesgos que ello implica ${ }^{4}$. Abensour (2007) expresa que "El siglo XX ha conocido formas de heró́smo totalitario, sea en la exaltación del soldado que busca la movilización total, sea en la glorificación del hombre nuevo" ( $p$. 257). Pero cabe anotar que el héroe, para Arendt, surge en y para la polis, siendo esta cualidad política del heroísmo lo que lo aleja de la tiranía y el totalitarismo. El héroe arendtiano no es un superhombre (como la historia oficial muestra a la mayoría de los "héroes") pues se trata de un heroísmo al alcance de todos, reconciliando así heroísmo y democracia. Además, ese heroísmo, siendo posible para todos, es también experiencia colectiva: es cuestión de un "nosotros", nunca de un "yo".
Arendt propone un coraje nuevo y paradójico que, según Abensour (2007), es el "heroísmo de los sin nombre" (p. 262). Como escribió Enrique Lihn (2009) en su Elegía a Ernesto Che Guevara:

Las condiciones de la tragedia están dadas, y no faltan los héroes;

más bien ellos forman ahora un ejército regular, un río subterráneo que se ramifica en los lugares estratégicos,

un un árbol subterráneo cuyo follaje es la tierra (...) y hay también el conducto de los héroes;

todos los héroes llevan a él como los pasos de una prueba de fuego;

(...) el signo de igualdad entre el que inicia la marcha y quienes le siguen guardando esa distancia camino de la lógica y del azar entremezclados "por el pantano cubierto de manglares"

Hay el hombre Ernesto Che Guevara cuyo nombre es legión, pero de hombres que avanzan a favor de la historia (...)

Ahora bien, el heroísmo revolucionario, más allá de visiones idílicas, no puede ocultar su problematicidad. Al tratarse de que prime la libertad en lo humano (lo que expresa la máxima zapatista "mejor morir de pie que vivir arrodillado") el revolucionario puede caer en el nihilismo por su disposición a sacrificar la propia vida (incluso la de otros) para salvaguardar la libertad. Indudablemente detrás de esta idea se oculta una idea absolutista -y no real- de la libertad. El espíritu revolucionario, para lograr su objetivo, requiere de una versión relativa y restringida de la libertad. Así lo propone Arendt: el heroísmo revolucionario es humano, es decir, reconoce su finitud; en caso contrario es martirio o sacrificio.

3 Teorizado por Arendt, sobre todo en¿Qué es la política?se basa en el coraje y el amor por la libertad de aquel que prefiere morir a la servidumbre: "sólo puede setibre aquel que está dispuesto arriesgar su vida" (2005, p. 83).

4 Seguimos aquí el trabajo de Miguel Abensour sobre el heroísmo revolucionario en Arendt. Ver Abensour, M (2007). Para una filosofía política crítica. Barcelona: Siglo XXI, págs. 257-263 
Uno puede concluir que para evitar este error la revolución requiere de una ética de los límites y de lo relativo, que no absolutice ningún extremo: ni rechazo o aceptación, ni singular o universal, ni individuo o historia $y$, sobre todo, ni libertad o vida. Sin esa reflexión permanente, el revolucionario se vuelve totalitario, torturador.

Hay que recordar que el verdadero héroe es intrépido: no es quien no tiene miedo, sino quien reconoce y supera su finitud y su temor a la muerte, comprendiendo que ésta sólo tiene sentido desde la libertad. Su fuerza es más interior que física: se trata del dominio de sí, que es aprendizaje como lo señalan los antiguos, sobre todo Doroteo de Gaza quien "recomienda comenzar por habituarse a quitar pequeñas cosas, una vana curiosidad, una palabra inútil, para prepararse poco a poco a mayores sacrificios" (Hadot 2000, pág. 367).

El héroe revolucionario no es entonces un superhumano, semi-dios y medio-hombre. El concepto aquí designa ante todo a esos héroes anónimos que, desde los "comuneros" colombianos hasta los "zapatistas" mexicanos y los "sansculottes" franceses, vivieron las revoluciones modernas. El héroe rerevolucionario nace $y$ vive entre gente corriente y vive problemas semejantes que generan empatía e identificación con él. Cuando Camus (1953) se pregunta a si mismo ¿Qué es un hombre rebelde?, responde que es: "Un hombre que dice no. Pero si niega, no renuncia: es también un hombre que dice sí, desde su primer movimiento. Un esclavo, que ha recibido órdenes toda su vida, de pronto juzga inaceptable un nuevo mandato" (p.27).

La vida del Che Guevara es el mejor ejemplo de heroísmo revolucionario en el Caribe americano. Nada lo predestinaba, nada lo obligaba a más. Su vida es paradigmática de múltiples cosas: heredero histórico de Simón Bolívar, alter ego espiritual de Fidel Castro, símbolo de la revolución moderna y "vengador" del Nuevo Mundo, no solo animó a muchos que se fueron a las armas, sino a buen número de intelectuales.
Su lección fundamental es que las ideas deben convertirse en acciones para no quedar reducidas a sueños. Creyó en la liberación, a cualquier precio, de los marginados y explotados latinoamericanos y de todo el mundo desposeído. ¿Qué significan la vida y la muerte del Che en términos simplemente humanos? Si eligió el no confort de la guerra y el riesgo de la muerte, fue porque una fuerza interior lo impulsaba a actuar y una causa lo llevaba a comprometerse: la libertad. Su enseñanza es que la esperanza siempre es posible. La experiencia cubana y boliviana del Che constituye un ejemplo representativo de lo que hemos llamado "coraje de la libertad".

\section{El coraje de la no-violencia (satyagraha)}

Aquí no se trata de negar el conflicto sino de participar en él sin violencia. El coraje de la noviolencia es resistir rechazando la posibilidad del "ojo por ojo" ante la crueldad o violencia del adversario. Ejemplos claros son la resistencia no-violenta o la desobediencia civil. Ante el agresor, el agredido puede optar por una de tres acciones: colaborar con él para salvarse, no hacer nada o evadir, o finalmente, resistir. Esta última acción es la más peligrosa pues resistir, puede hacerse o con violencia o sin ella. Quienes resisten sin violencia, generalmente, actúan así porque no tienen armas, y no tanto por convicción. El ejemplo de Gandhi resulta para muchos incomprensible: ¿cómo un grupo de individuos desarmados resiste o actúa contra un adversario que tiene armas y seguro no dudará, si es necesario, utilizarlas? $\mathrm{Y}$ es incomprensible porque implica un doble coraje: resistir (decir "no") y resistir sin armas, es decir, con conciencia de su debilidad frente a su adversario. Un ejemplo: El desafío de Gandhi en 1930 al colonialismo británico sobre el monopolio de la sal desencadenó una ola de desobediencia civil que ayudó a la expulsión del imperio británico. Las leyes de la sal gravaban su producción por lo que el país importaba sal británica. Gandhi y sus partidarios iniciaron una 
marcha para producir sal india y trasladarla sin pagar el impuesto: los británicos oprimieron la marcha, detuvieron a miles, y se negaron a realizar cualquier concesión. Sin embargo, la resistencia generó efectos a largo plazo que subsanaron su incapacidad para lograr los objetivos deseados. Primero, sirvió de inspiración a quienes participaron (la mayoría no se habían organizados antes); segundo, anunció al mundo que los hindúes eran una fuerza a considerar, y que el gobierno británico se había visto obligado a negociar con su líder; tercero, estimuló otras acciones de desobediencia civil; y, por último, tuvo una alta influencia en el pensamiento y la estrategia de otros como Martin Luther King. Se podría señalar asimismo la ola de movilizaciones noviolentas contra las dictaduras militares del Salvador, Guatemala y Nicaragua que llevaban años en el poder, en 1944.

Gandhi (2007) explica el porqué de este coraje: "el objetivo del desobediente consiste en convertir, no en constreñir, a aquel que hace el mal" (p. 140). Pero la vida y la historia muestran que persuadir mediante la razón no siempre se logra. Entonces, ¿con que otro mecanismo se puede convencer al adversario político de su error? Gandhi (1990) responde: "Para obtener un resultado decisivo no basta convencer a la razón; hace falta igualmente tocar el corazón" (p. 162); cuando persuadir con el discurso racional ha fracasado, hay que usar medios no racionales. Según Gandhi, aceptando voluntariamente sufrir, el desobediente expresa su convicción; hay que sacrificarse para llegar al corazón del adversario y despertar su conciencia adormecida: a quien me golpea yo debo, como Jesús lo enseña, ofrecer la otra mejilla. Gandhi (1960) lo dice claramente:

Yo busco despuntar completamente la espada del tirano, no atacándolo con un acero mejor afilado, sino engañando su expectativa de verme ofrecer una resistencia física. Encontrará en mí una resistencia del alma que sale de su alcance. Esta resistencia primero lo enceguecerá y después lo obligará a inclinarse (p. 110).
Así, el coraje es una condición de la acción noviolenta. Para persuadir hay que oponerse sin violencia. Pero es útil recordar aquí los planteamientos de muchos (entre ellos Weber) que recuerdan que la ética del Sermón de la montaña sólo vale en las relaciones entre individuos, pero no entre grupos y naciones; es algo ético y para nada destinado a la política. Entonces hay que reconocer que la audacia de Gandhi es justamente politizar esta ética, lo que tiene un doble interés: por una parte, reintroduce la ética en el escenario frío y cínico de la política; por otra parte, valida la acción no-violenta como forma innovadora para resolver conflictos.

El coraje de la no-violencia, como se dijo de los dos anteriores (verdad y libertad), vale también a nivel intelectual: se trata de romper con la ideología de la violencia que funciona como "verdadero chantaje en los ciudadanos al afirmar que la única forma de ser valientes es ser violentos, llamándolos cobardes si no lo son" (Muller 2005, p. 77). Es cierto que, frente a un conflicto extraño, hay que elegir entre intervenir o mantenerse alejado; pero es falso creer que la única forma de intervenir es la violencia. Rechazar la alternativa dualista (violencia/cobardía) e introducir la opción de una acción no-violenta, es coraje intelectual en tanto que va en contra de la cultura dominante que no deja de justificar sutilmente el uso de la violencia.

\section{El imposible, pero necesario oficio de maestro: el coraje de enseñar}

Sócrates es uno de los más claros ejemplos de un maestro de vida. Para él la educación es una vocación que no se puede prostituir con el salario que se reciba a cambio, pues solo hay un bien, que es la sabiduría, y solo hay un mal, que es la ignorancia. $Y$ la sabiduría consiste en el conocimiento y cuidado de uno mismo, lo que permitirá conocer la realidad, en su totalidad holística y compleja. Hay que distinguir entre un "enseñador sofista" y el "educador socrático". 
Ambos modelos se pueden incluir en la categoría de maestro (didáskalos). Pero, sobre todo en el Protágoras (311a-314b), Sócrates se identifica implícitamente con la figura del "médico del alma", del maestro que examina el alma del discípulo: no se propone depositar nada en él, sino iluminar, es decir, lograr que el propio discípulo discierna cuáles son las creencias que sostienen sus propios deseos, y los deseos que sustentan cómo habría de vivir (esta sería, en últimas, la finalidad didáctica). El logro del maestro no sería entonces depositar nuevos conocimientos, sino favorecer que el discípulo pueda decir lo que realmente cree, siente y quiere, y así despejar de su espíritu los discursos ajenos; que el discípulo pueda, en otros términos, responder con sus propias creencias a sus deseos y sus actos específicos. Y que haciéndolo se convierta en un auténtico ciudadano o sujeto político.

No es que Sócrates lo sepa todo; al contrario, su estilo es aprender dialogando. Conversa con sus discípulos y su método es novedoso: parte del juicio que cada cual tiene sobre las cuestiones de la vida que él les plantea; examina y cuestiona sus respuestas, suscitando la reflexión crítica. Sócrates es un hombre que busca, pero con el otro; sabe que a dos (o a varios), se aprehenderá mejor la verdad de lo que existe. Bien conducido el diálogo hace estallar las falsas ideas; genera, progresivamente, la unanimidad, ayudando a encontrar la verdad. $\mathrm{Y}$ siempre hay un tercero ausente con el que se dialoga, que hay que buscarlo más allá de la opinión, y que se llama verdad: es en el entredos del diálogo que surge ese tercero que es lo verdadero.

¿En qué consiste el quehacer y el oficio del maestro? ¿Qué nivel de responsabilidad y autonomía tiene en el proyecto educativo, de sociedad y de país?
¿Qué cambios en el proceso de aprendizaje y enseñanza son posibles desde su quehacer profesional? ¿Qué importancia tienen sus prácticas docentes frente a las teorías pedagógicas vigentes? Todas esas y muchas más son cuestiones que ayudan a definir o perfilar la problemática de ese oficio, imposible pero necesario, del maestro. Aquí se trata, entonces, de las condiciones de una praxis educativopedagógica que conserve el sentido de la praxis aristotélica de no reducirse a la simple y pura producción de saberes, o peor, de estructurar un sujeto responsable sino de lograr el advenimiento de las acciones y palabras de las que los estudiantes, sin importar el nivel en que estén, puedan ser plenamente sus autores, en un contexto de construcción de ciudadanía. Porque es en términos de praxis como hay que pensar las profesiones imposibles y las prácticas pedagógicas; en términos de ese concepto aristotélico enriquecido hoy con la idea marxista de que la praxis es portadora -y ella misma es guiada- por esa temporalidad propiamente humana (historia), constituida en el orden de lo posible, de la alteridad/alteración, de la creación, de un proyecto emancipador, es decir, praxis comprometida que suponen siempre el coraje y la valentía.

Esta misma problemática ha sido desarrollada por Meirieu (1998) cuando plantea la cuestión de la producción del sujeto educativo tomando como modelos referenciales los desastrosos resultados que narran las historias del monstruo de Frankenstein, Pigmalion, Pinocho, Robocop, etc. La quimera manufacturera se estrella, tarde o temprano, con un sujeto que ofrece resistencia al poder que se pretende ejercer sobre él, dado que su libertad siempre escapa a la voluntad del maestro. La relación educativa hay que construirla, pues, en una acción que permita la aparición de un sujeto que desea y habla en nombre propio, como un verdadero ciudadano. 


\section{A modo de conclusión}

Se han presentado algunas figuras del coraje en su sentido político: el militante, el revolucionario, el desobediente no-violento y el maestro. Y ello plantea otras problemáticas: ¿el coraje ciudadano implica ser militante $\mathrm{o}$ revolucionario? ¿Son compatibles las nociones de no-violencia y de verdad? ¿Es posible ser revolucionario sin ser violento? ¿Ser auténtico maestro es necesariamente ser revolucionario o militante político?

Hay que confrontar la no-violencia del desobediente con la verdad del sujeto ciudadano porque son sus formas específicas de coraje. Y quien ha mejor teorizado esta cuestión es, como se ha visto, Gandhi. La sociedad política siempre es espacio de confrontación de diversas verdades; todas con propósitos correctos pero parciales. Y normalmente, los individuos no asumen la relatividad de su verdad. La historia muestra siempre que aquel que cree poseer la Verdad absoluta (sea religiosa, política o científica) es capaz de espantosos crímenes para defenderla5. La pregunta entonces es: ¿cómo Gandhi mantiene una idea de la política como búsqueda de la verdad, evitando al mismo tiempo que la acción política termine siendo autoritarismo o anarquía? La respuesta es en el fondo muy sencilla: mediante la distinción entre Verdad absoluta y verdades relativas. Si la Verdad existe, no podemos llegar a ella; sólo conocemos verdades relativas, por eso no se puede juzgar o castigar al otro por tener otra verdad. Y por eso, "Si la verdad no implica por sí misma la deslegitimación radical de la violencia, entonces llegará siempre un momento en el que la violencia aparezca como un medio legitimo para defender la verdad (Muller 2008, p. 139). Gandhi, consciente de ello, había ligado sólidamente la no-violencia a la verdad para que esta última no termine en conflicto armado.
Ahora bien, ¿el coraje ciudadano en cualquiera de sus vertientes (decir veraz, enseñar a ser reflexivo y crítico, desobedecer) implica siempre ser revolucionario? Habría que (re)conceptualizar la noción de revolución, pues por lo general se asocia "violencia" con "revolución". Sin embargo, la historia reciente muestra múltiples acciones de resistencia civil noviolenta, lo que invita a considerar la posibilidad de que el ciudadano sea revolucionario sin ser violento. Entendiendo que todo o casi todo ya ha sido dicho y reflexionado respecto de la versión "violenta" de la revolución, una revolución no-violenta es históricamente posible (Juliao, 2007 pág. 168). Esta realidad podría conducir a replantear la filosofía política tradicional, y sobre todo a reconsiderar el rol político del oficio de enseñar.

5 El riesgo de una política fundada en una supuesta verdad absoluta es importante porque su búsqueda culmina en la guerra santa de los tiempos modernos. La historia, escribe Gandhi, nos enseña que "millares de atrocidades han sido cometidas a nombre de Dios". Gandhi asegura no conocer "mayor pecado que oprimir al inocente a nombre de la verdad". 


\section{Referencias}

Abensour, M.(2017). Para una filosofía politica critica. Barcelona: Siglo XXI

Arendt, H.(1972). "La désobéissance civile” en Du mensonge à la violence. Paris: Calmann-Lévy

Arendt, H.(2005). ¿Qué es la política? Barcelona: Paidos

Camus, A. (1953). El hombre rebelde. Buenos Aires: Losada

Cervera-Marzal, M.(2012). "Le courage comme vertu cardinale du sujet politique", Variations

Consultado el 15 enero 2017 en http:/ /

journals.openedition.org/variations/ 364

Foucault, M.(2008). "Le courage de la vérité: l'ascète,

le révolutionnaire et l'artiste" en Esprit, Paris págs. 51-60

Gandhi (1960). Lettre à l'ashram. Paris: Albin Michel

Gandhi (1990). Tous les hommes sont frères. Paris:

Gallimard

Gandhi (2007). Résistance non-violente. Paris: Buchet/

Chastel

Gros, F. (2006). Etats de violence, Essai sur le fin de la guerre. Paris: Gallimard
Hadot, P. (2000). ¿Qué es la filosofía antigua? México: FCE

Juliao, C. (2007). Educación social. El Minuto de

Dios: una experiencia y un modelo. Bogotá:

Uniminuto.

Lihn, E. (2009). "Elegía a Ernesto Che Guevara" en Anaquel Austral. Santiago: Editorial Poetas Antiimperialistas de América.

Recuperado de http://virginia-vidal.com/ anaquel/el_poema/article_301.shtml > Meirieu, Ph. (1998). Frankenstein educador.

Barcelona: Laertes.

Muller, J-M. (2005). Dictionnaire de la non-violence.

Gordes: Les Editions du Relié

Muller, J-M. (2008). Le courage de la non-violence:

Paris: Les Editions du Relié

Thoreau, H. (2007). La désobéissance civile. Paris:

Le passager clandestin

Weil, S. (1960). "Réflexions pour déplaire" en

Ecrits historiques et politiques. Paris: Gallimard 